\title{
Article \\ The Function Design for the Communication-Based Train Control (CBTC) System: How to Solve the Problems in the Underground Mine Rail Transportation?
}

\author{
Haoxuan $\mathrm{Yu}^{1,2}$ and Shuai $\mathrm{Li}^{1, *}$ (D) \\ 1 School of Resources and Safety Engineering, Central South University, Changsha 410083, China; \\ yuhaoxuan@csu.edu.cn \\ 2 Institute of Electrical and Electronics Engineers (IEEE), New York, NY 10001, USA \\ * Correspondence: shuaige@csu.edu.cn
}

\section{check for}

updates

Citation: Yu, H.; Li, S. The Function Design for the Communication-Based Train Control (CBTC) System: How to Solve the Problems in the Underground Mine Rail Transportation? Appl. Syst. Innov. 2021, 4, 31. https://doi.org/ $10.3390 /$ asi4020031

Received: 14 April 2021

Accepted: 26 April 2021

Published: 27 April 2021

Publisher's Note: MDPI stays neutral with regard to jurisdictional claims in published maps and institutional affiliations.

Copyright: (c) 2021 by the authors. Licensee MDPI, Basel, Switzerland. This article is an open access article distributed under the terms and conditions of the Creative Commons Attribution (CC BY) license (https:// creativecommons.org/licenses/by/ $4.0 /)$.

\begin{abstract}
With the continuous development of the mining industry, the world's major mines have gradually entered the intelligent stage. In intelligent underground mines, the operation roads of the underground transportation equipment are very complicated, and the monitoring and control of the underground traffic have become the problems to be solved in the intelligent underground mines. Therefore, on the basis of solving the practical problems of underground mines, the concept paper discusses the possibility of the communication-based train control (CBTC) system being applied to underground mines through the summary and induction of the related literature. As mining engineers, we have proposed the function design for the CBTC system to solve the problems in underground mine rail transportation, but we still need to continue to work hard for the future development of the underground mines. The concept paper serves as a guide to the Tossing out a brick to get a jade gem, and it has implications for the development and the future of underground mine transportation.
\end{abstract}

Keywords: underground mines; rail transportation; underground transportation; monitoring and control system; mining industry

\section{Introduction: The Development of the Mining Industry and the CBTC System}

With the rapid development of mining science and technology, the underground mines all over the world are gradually stepping into the intelligent stage.

Although the intelligentization is the ultimate goal of mine development, underground mine faces many challenges in the process of developing toward the intelligentization, especially underground transportation. Frankly speaking, in the past 20 years, many researchers have devoted themselves to the research of intelligent underground mines, including the research of intelligent underground mine transportation [1].

In the year 2020, Dong et al. [1] committed to the research of underground intelligent mine autonomous driverless vehicles, and they made a great breakthrough on the function of Velocity-Free Localization of the underground vehicles. In the same year, Chen and Wang [2] published their research progress of safety monitoring in the underground coal mine, and Meng and Li [3] achieved the application of Internet of Things technology in the underground mine. Earlier before in 1999, MacLeod and Stothert [4] proposed intelligent control of the underground mine refrigeration system. As early as in 2008, Zheng and Cai [5] put forward the intelligent system in underground mine production. While in 2013, Zhen [6] made great achievements in the research of underground ventilation monitoring system in coal mine.

For underground mines, with the continuous development of mining transportation industry, rail transport has gradually been replaced by trackless transport. However, there is no doubt that the monitoring and control of trackless transportation in intelligent 
underground mines is not as convenient as that of rail transportation. Therefore, in recent years, some mining enterprises have started to try to run rail transportation in intelligent underground mines, and they achieved good results, especially in China, whose mining industry development is relatively behind. Although rail transportation of the intelligent underground mine is not as flexible as trackless transportation, rail transportation has low operating costs and is widely used.

For the above-ground Urban Rail Transit, the CBTC (Communication-based Train Control) system is a common signal control system in the Urban Rail Transit System [7]. Admittedly, the CBTC system is not perfect either, but with the maturity and development of Internet of Things technology, the combination of CBTC system and Internet of Things technology will develop the CBTC system, which has become an academic consensus [8].

The CBTC system has a long history, being first used in practice and having been improved based on IEEE standards [9,10]. In 2003, Vantuono [11] noted that the CBTC system was gradually beginning to be piloted worldwide. In 2005, New York began planning to implement the CBTC system according to the report of Alexander and Mortlock [12]. Around 2010, even some Chinese researchers [13,14] have achieved quite good results in the research of the CBTC system.

By the 2010s, the CBTC system had developed rapidly. Bu et al. [15] and Zhu et al. [16] put forward some suggestions for optimizing some functions of the CBTC system around 2014. In 2016, Wang, Yu, and Jiang [17] improved the functionality of the WLAN in the CBTC system. Around the year 2017, Farooq et al. [7] evaluated the wireless communication network performance of the CBTC system and suggested that the system could be further optimized; Farooq and Soler [8] did a survey on the CBTC system, and the survey showed that many researchers believe that the combination of CBTC system and Internet of Things technology could develop the CBTC system. Specially, in the research of Wang et al. [18,19] around 2019, they focused on the safety protection and communications of the CBTC system, and they improved the CBTC system's wireless communication system by the Q-learning method based on LTE-T2T and obtained excellent application results. Recently, Liu et al. [20] focused on combining the CBTC system with artificial intelligence computing (AI Computing).

The CBTC system has been used in the above-ground Urban Rail Transit always. In 2015, Wang, Zhao, and Chen [21] thought that the CBTC system is suitable for the above-ground urban traffic monitoring, and they also believed that the operation of the CBTC system in urban traffic is a process of trial and error, because the monitoring of above-ground traffic can reduce the error of the monitoring conveniently by artificial reconnaissance and surveillance.

Unlike the above-ground Urban Rail Transit, the monitoring of the underground rail transportation is not susceptible to the artificial reconnaissance and surveillance because of the intricacies of the underground rail traffic. As well, the above-ground traffic control system is mainly to ensure the safety of the traffic and the train departure planning, but it is different in the underground mine rail transportation. In general, the above-ground traffic control system is mainly for the service of passengers, and the underground mine rail transportation is mainly for transport efficiency. Therefore, if the CBTC system is to be applied to underground mines, it is necessary to make some functional changes to the CBTC system.

At present, the CBTC system is a relatively advanced control system for the aboveground vehicles, which is applied to urban rail transit lines in various countries even developing countries. Years ago, Sun et al. [22], Si, Kuang, and Li [23] all paid attention to the running cost of the CBTC system and explored the possibility of its application in cities of developing countries such as China.

For the current CBTC system, the train control center that coordinates and manages all trains running on the line is at the top level of the CBTC system, including the ATS (Automatic Train Supervision) system. Zhu et al,. [24] researched the anti-interference 
ability of the CBTC system to optimize the Supervision Function of the ATS system in the year 2020.

The Data Communication System transfers data between modules, including wired and wireless communication network equipment. In 2018, Wen et al. [25] had already made a great breakthrough on the Access Point Deployment Optimization in the CBTC Data Communication System, and they emphasized the importance of the Data Communication System as the signaling medium of the CBTC system. Additionally, individual vendors have Data Communication System independence as subsystems.

The on-board system includes the ATP (Automatic Train Protection) system, the ATO (Automatic Train Operation) system, man-machine interface, and so on. The internal system of the station includes the zone controller system, data storage system, CI (Computer Interlocking) system, and so on. The unified operation of these systems is able to realize the interlocking and calculation of the station and the train. The transponder and axle counting system of the on-board system are installed beside the track (on the track side) to realize the real-time monitoring and position calibration of the incoming and outgoing trains.

In 2013, Wang et al. [26] raised the importance of the overall coordination of the CBTC system; only through the combined operation of these systems can the functions of train safety protection, automatic driving, driver's communication and interaction be realized.

Figure 1 shows the CBTC system's structure.

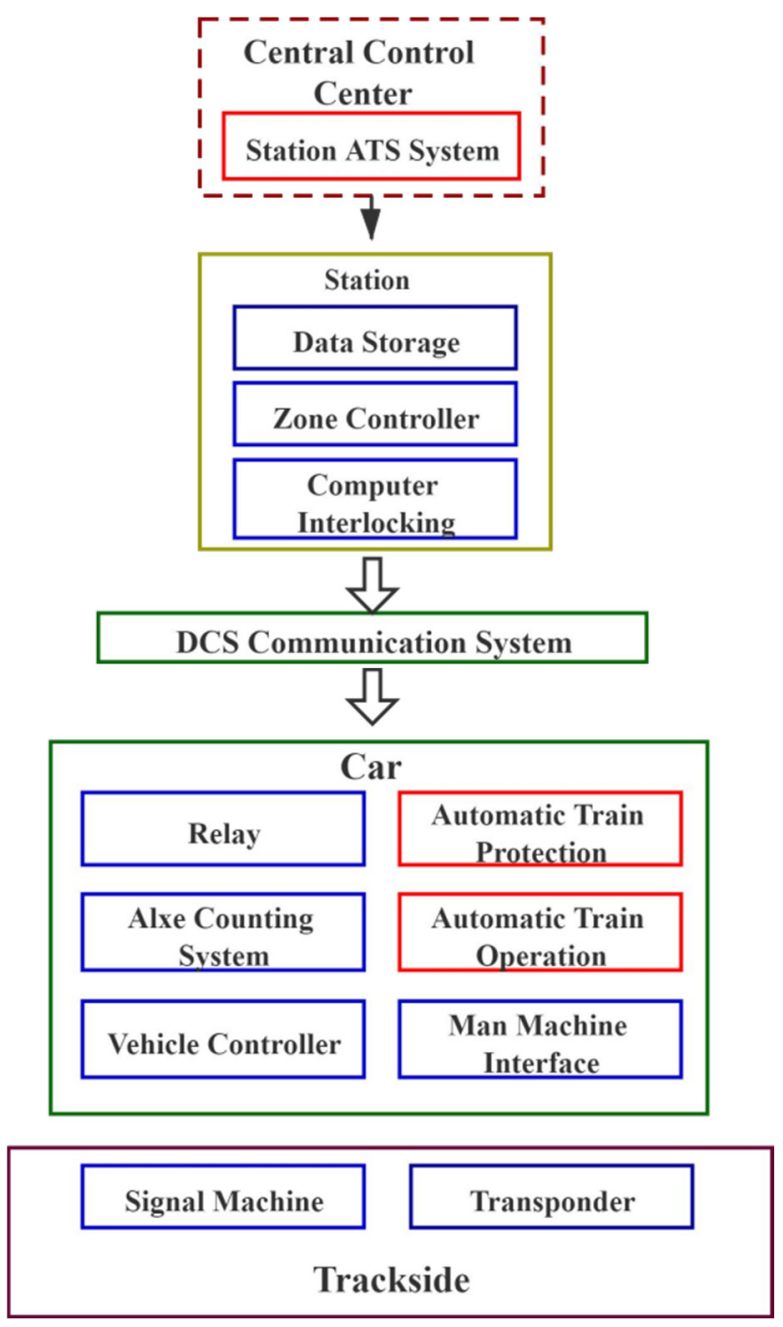

Figure 1. The structure of the CBTC system. 
The ATP system (Automatic Train Protection), the ATO (Automatic Train Operation) system, and the ATS (Automatic Train Supervision) systems are the three most important subsystems to ensure the operation of the CBTC system. In the three systems, the ATS system is the core of the CBTC system; it is a monitoring system based on a series of programs such as big data processing and computing, computer network sharing and real-time signal data conversion, it cooperates with the ATP system, the ATO system, the $\mathrm{CI}$ (Computer Interlocking) system, and other systems to realize the real-time monitoring, information collection, resource allocation, and utilization of the Urban Rail Transit System.

Figure 2 shows the structure of the ATS system, and Figure 3 shows the specific functions of the ATS system.

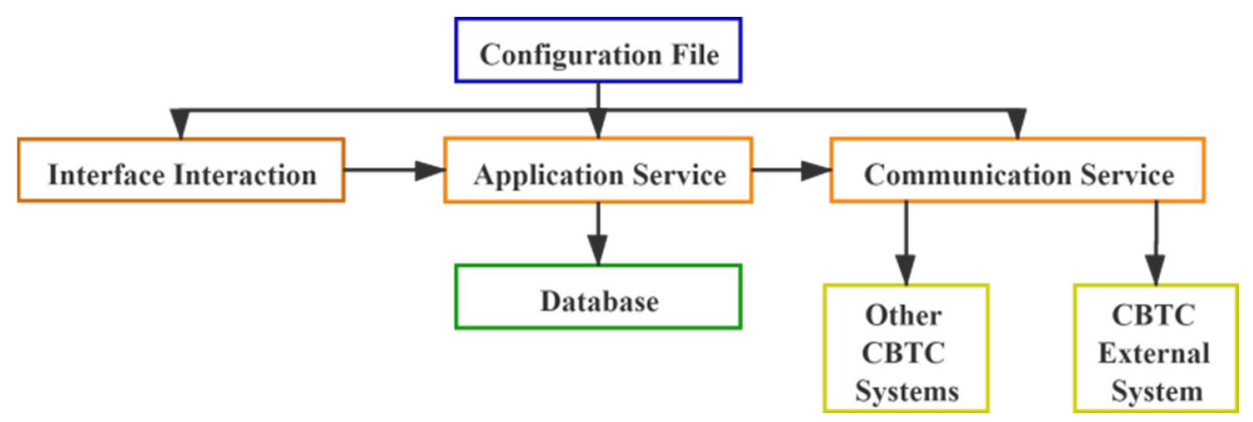

Figure 2. The structure of the ATS system.

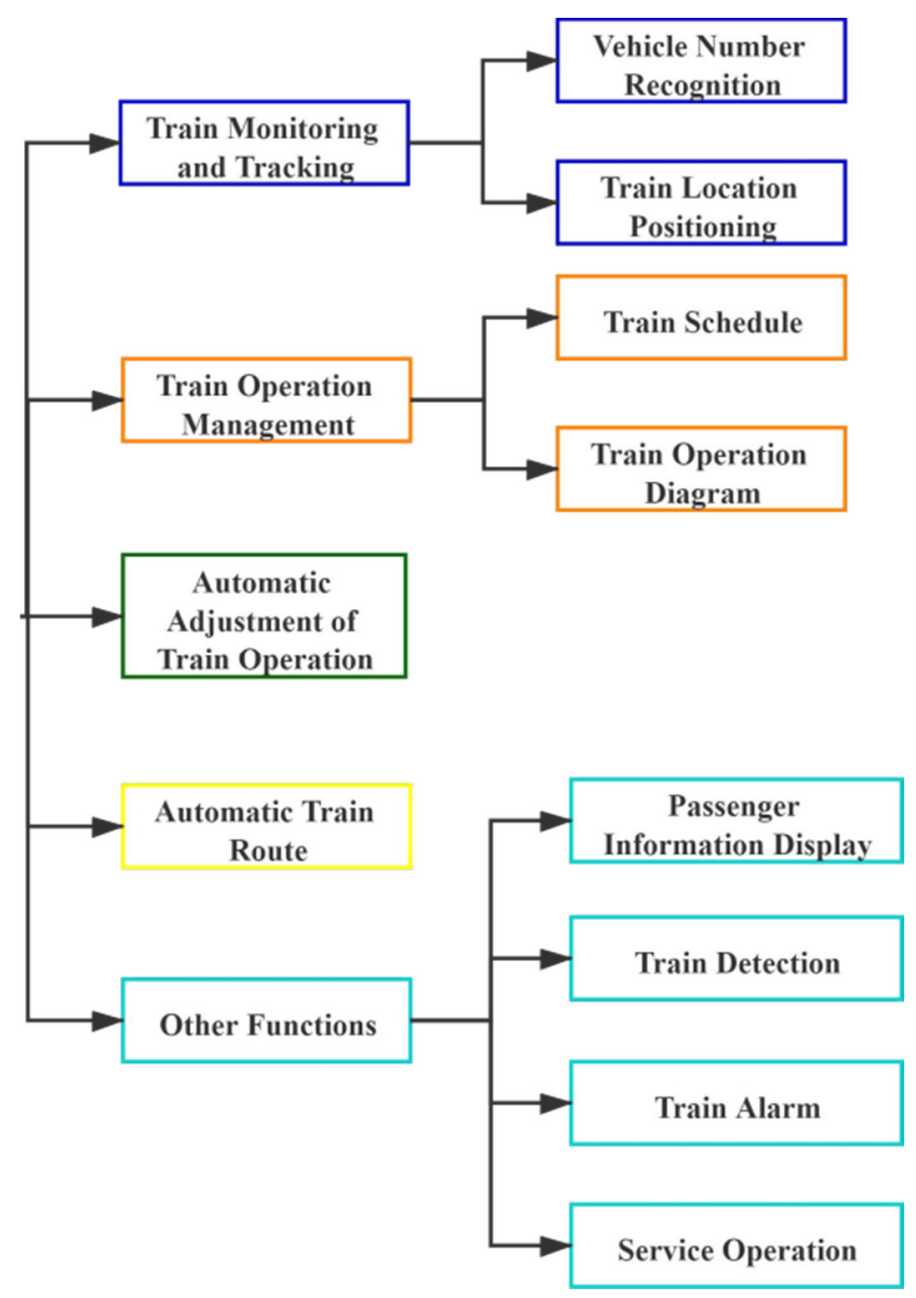

Figure 3. The functions of the ATS system. 
Specially, the CBTC system not only has an excellent application effect above ground, but it also has a great application effect in the operation and monitoring of the underground subway [27]. As a kind of underground rail transport, subway is also not susceptible to the artificial reconnaissance and surveillance, so in 2016, through the improvements of the CBTC system, Carvajal-Carreño, Cucala, and Fernández-Cardador [27] tried to applied the monitoring and tracking functions of the CBTC system to the subway transport and made good progress. In fact, as early as in 2006, Bin et al. [28] put forward the concept of creating an underground city and suggested that the CBTC system should be the main traffic control and monitoring system under the ground. In 2013, Wang et al. [25,29] published their research on the underground simulation of the CBTC system in the 2013 IEEE International Conference on Communications (ICC), and in 2014, Briginshaw [30] explored whether the CBTC system could be used in underground traffic in London. However, by 2015, underground traffic control and communications based on the CBTC system seemed to have been achieved according to the research of Aziminejad, Lee, and Epelbaum [31]. Through the news reports [32], by 2019, London had fully automated subway operations based on the CBTC system.

Although the running environment of underground mine transportation is similar to that of subway, the running of subway is mainly for the service of passengers, similar to Urban Rail Transit. Therefore, as the CBTC system can be used in the running of underground subway to some extent, with this precedent, it is believed that the CBTC system can be used in the intelligent underground mine after apposite improvements.

In a nutshell, this concept paper briefly introduces the progress in the present stage of the research to apply the CBTC system, especially the three systems (ATO system, ATP system, and ATS system) to the underground transportation in order to solve the practical problems in the engineering of transportation in underground mines.

\section{The Concept and Design: The Function Design of the CBTC System}

\subsection{The Background of the Practical Problems}

In the majority of the underground mines of the world, the main transport equipment on the track is electric locomotive, which is call-replaced by transport units in the following text.

In 2015, Dash et al. [33] raised the opinion that although rail transport is more convenient than trackless transport in the underground mines, there are still many problems to be solved, such as safety accidents and transport efficiency; the problems to be solved urgently in underground mines are mainly the following three: (A) Safety Problem-The rear-end collision problem; (B) Efficiency Problem-The transport efficiency problem; and (C) Monitoring and Control-The real-time monitoring problem.

\subsection{The Function Design of the CBTC System for the Solutions to the Practical Problems}

In order to solve the practical problems of transportation in underground mines, the concept paper tries to summarize and propose the solutions to the above problems by applying and ameliorating the CBTC system, especially the three systems (ATO System, ATP system and ATS system) according to the related literature and the previous successful experiences.

The following is the function design of the CBTC system for the solutions to the practical problems.

\subsubsection{Safety Problem: The Rear-End Collision Problem}

The ATP (Automatic Train Protection) system is the core system to control the speed of the transport units and the safe distance between the front and rear transport units. The ATP system controls and regulates the minimum interval and over-speed protection in the operation of the transport units to avoid the rear collision of the transport units. Its main components include range measurement equipment, vehicle speed monitoring equipment, vehicle-ground interaction equipment, and emergency braking equipment. It should be 
noted that in the rail transportation of an intelligent underground mine, the maximum speed of the transport units should not exceed $40 \mathrm{~km} / \mathrm{h}$ in order to avoid rollover caused by track bump. Therefore, in the application of the ATP system, when the speed of the transport units is detected to exceed $40 \mathrm{~km} / \mathrm{h}$, it will be slowed down by the control system.

At the 2020 IEEE 23rd International Conference on Intelligent Transportation Systems (ITSC), Gao et al. [34] published research on the safety function of the ATP system, and they proposed a new analysis method for the ATP system, the Dynamic Fault Tree analysis method. The Dynamic Fault Tree is a system of methods for evaluating the reliability and safety of a complex system, and it is also a kind of deductive method, which is based on the fault event and is analyzed step by step according to the top-down sequence through certain logical reasoning steps until the result is reached. The Dynamic Fault Tree analysis method is devoted to modeling the fault logic according to the dynamic fault behavior, and it conforms to the functional design of the signal system. It is worth mentioning that logical analysis based on the Dynamic Fault Tree analysis method often analyzes the emergence of problems at the same time, instead of analyzing it layer by layer, which can greatly improve the efficiency of problem solving.

The order of problem solving based on the Dynamic Fault Tree analysis method is as follows: (1) Identify the possible fault events. (2) According to the possible fault events, establish the analysis process of them. (3) Through the control system (as in the ATP control system), analyze whether the fault events occur. (4) If the fault events occur, solve them through the control system (as in the ATP control system).

For the ATP system, the fault events in the underground transportation might caused by over speed, the safety distance, Vehicle Rollover, or an emergency. Therefore, the analysis of the fault events has been established as follows: (1) Is the speed of any transport unit over $40 \mathrm{~km} / \mathrm{h}$ ? (2) Are all transport units within a safe distance? (3) Have there been any rollovers? (4) Has an emergency appeared?

Through the monitoring and control functions of the ATP system and other auxiliary functions, the rear-end collision problem could be solved with the assistance of the Dynamic Fault Tree analysis method: (1) If the speed of the transport units is detected to exceed $40 \mathrm{~km} / \mathrm{h}$, it will be slowed down by the control function of the ATP system. (2) If the distance between the transport units may cause an accident, the distance will be controlled by the control function of the ATP system through controlling the speed of the transport units. (3) If a vehicle rollover accident is detected, the control function of the ATP system will halt the transport units nearby the accident. (4) If the emergency appears, the control function of the ATP system will halt all transport units in the underground mine.

With the improvements based on the Dynamic Fault Tree analysis method, the control function and working principle of the ATP system in the intelligent underground mine are shown in Figure 4. 


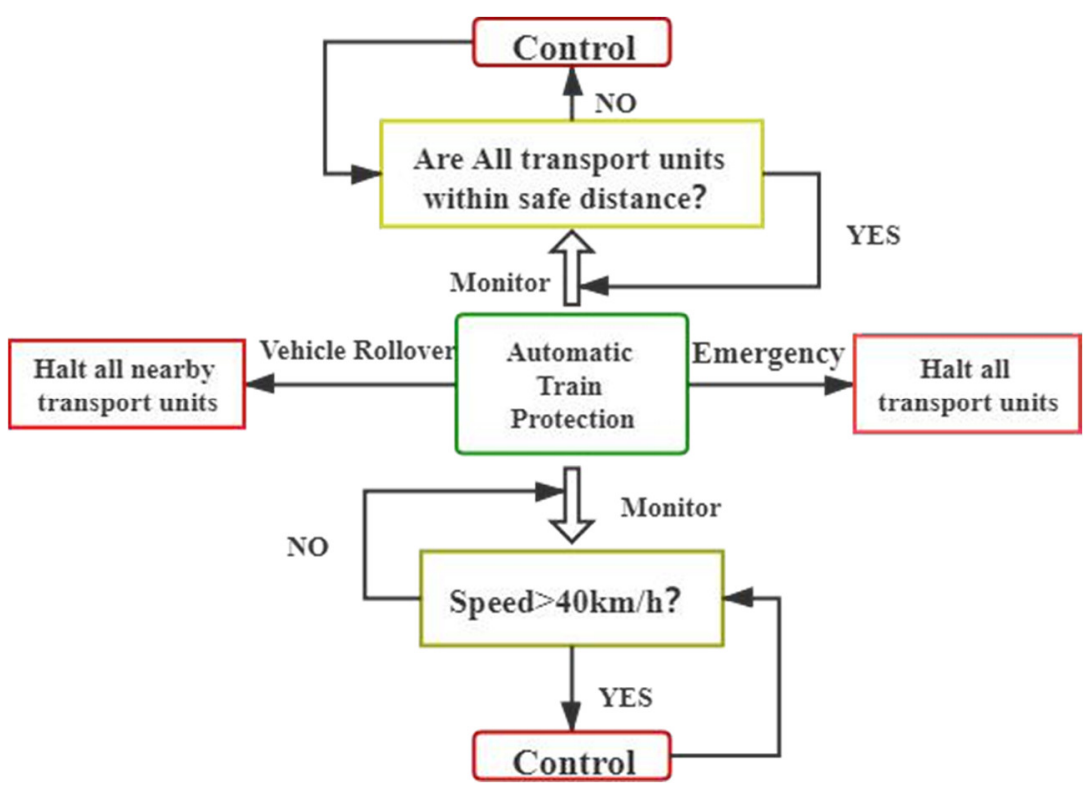

Figure 4. The control function and working principle of the ATP system in the intelligent underground mine.

\subsubsection{Efficiency Problem: The Transport Efficiency Problem}

The distance and speed information of the transport units are collected by the ATO (Automatic Train Operation) system and transmitted to the ATP (Automatic Train Protection) system, and they both together control the speed of all transport units to maximize the efficiency of the intelligent underground mines. In 2019, W. Wu and B. Bu [35] emphasized the crucial role of ATO system in security analysis, and they put forward their viewpoint that although the ATP system is the core system of the security of the CBTC system, the ATO system provides the significant information of speed and the distance of the transport units. The vital information not only works in the security monitoring of the ATP system but also plays an important role in the supervision and tracking of the ATS system. To put it simply, all thanks to the useful information of the speed and distance of the transport units provided by the ATO system, the ATP system and ATS (Automatic Train Supervision) system can achieve their respective control and monitoring functions.

As is known, the transport efficiency of the underground mine is determined by the speed of transport units to some extent. Therefore, both the ATO system and the ATP system are indispensable to make the underground mine transportation achieve its maximum transport efficiency. It is worth mentioning that calculating the speed of each transport unit when the maximum transport efficiency can be achieved is what the ATP system or ATO system could not accomplish, so it is essential to draw support from the calculating function of AI computing.

To solve the problem, first, it is necessary to establish a single analysis of the fault event on the basis of the Dynamic Fault Tree analysis method: (1) Has the underground mine achieved maximum transport efficiency? Through the monitoring and control functions of the ATP system, the information-providing function of the ATO system, and other auxiliary functions, transport efficiency problem could be solved with the assistance of the Dynamic Fault Tree analysis method and AI Computing: (1) The ATO system provides the significant information of speed to the ATP system, and the ATP system controls the speed of each transport unit until the underground mine transportation achieves the maximum transport efficiency by the sustained calculating progress of AI Computing.

With the improvements based on the Dynamic Fault Tree analysis method and AI Computing, the functions and working principle of the ATO system and ATP system efficiency adjustment function in the intelligent underground mine are shown in Figure 5. 


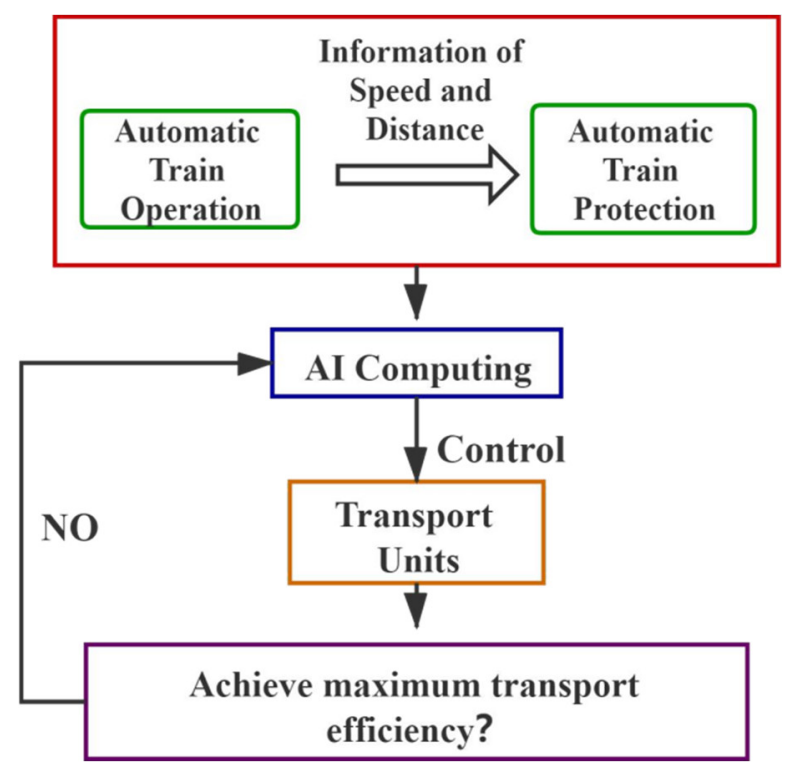

Figure 5. The function and working principle of the ATO system and ATP system efficiency adjustment function of the intelligent underground mine.

\subsubsection{Monitoring and Control: The Real-Time Monitoring Problem}

The real-time monitoring of the transport units is the biggest problem in intelligent underground mines. If the real-time monitoring of the transport units can be realized, it will be greatly beneficial to the mining industry-for example, the monitoring of mine accidents and the search and rescue of personnel. In 2012, Xue and Wei [36] researched the intelligent track positioning system so as to solve the problem of the mine accident rescue, and they thought if the monitoring and tracking functions would be realized, the mining industry will enter a new stage of rapid development.

As the core of the CBTC system, AI Computing ATS system is divided into linear, centralized control, centralized monitoring, and decentralized control, which is used to realize the real-time monitoring, unified dispatching and management of transport units. In 2016, Gurník [37] raised his prospect of the NGTC (Next-Generation Train Control) project, combining the CBTC (Communication Based Train Control) system with the ETCS (European Train Control System) system. He thought that most subsystems of the CBTC system should be replaced, but only the ATS system should remain because of its advanced supervision function. In urban above-ground transportation, ATS system functions include train monitoring and tracking, train time and operation management, automatic train routing, and automatic train adjustment, as shown in Figure 3 above.

In 2010, Feng et al. [38] made great achievements in the research of the Wireless Mobile Monitoring System for Tram Rail Transport in an Underground Mine, but they considered there was still a large amount of problems to be solved regarding the real-time monitoring and control of underground mines. In the year 2015, Ali et al. [39] tried to solve the problems of real-time monitoring and control of underground mines; they thought there were four main problems in the real-time monitoring of underground mines: (1) the real-time monitoring of the transport units; (2) the start-up time control of the transport units; (3) the route adjustment of the transport units; and (4) transport units tracking.

$A$. The real-time monitoring of the transport units

It is necessary to monitor and control the transport units in real time because of the intricacies of the underground rail traffic; meanwhile, the identification of the transport units is also essential.

Firstly, each transport unit is required to be numbered, and a signal transmitting device that can be recognized by the number of recognition sensors on the track is arranged on each transport unit. Identification information is transmitted to the ATS on-board extension via an optical cable and compared with the transport unit number in the number 
database. If the transport unit number recognized by the ATS system does not match the information in the number database, three possibilities of the error are automatically identified: (1) manually modified information; (2) wrong number; or (3) lost number. In the case of manually modified information, the system retains the current transport unit number; otherwise, the system re-assigns a new number to the current transport unit.

The Number Recognition and Repair Function is shown in Figure 6.

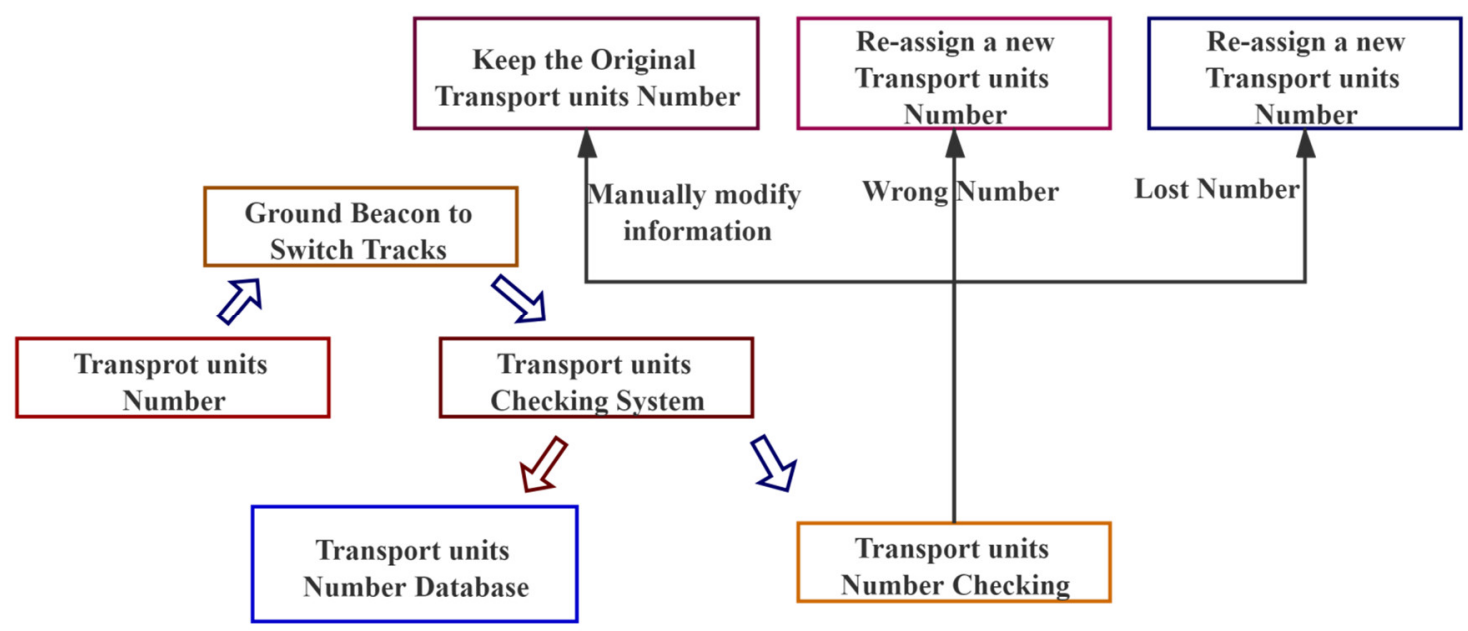

Figure 6. The Number Recognition and Repair Function.

In 2018, Mazzanti and Ferrari [40] combined Internet of Things technology with an ATS system using sensors on the track to monitor the train in real time. In addition, the number recognition sensors scattered throughout the track not only have the transport unit identification function but also transmit the position information of each train to the ATS system in real time. The ATS system continuously monitors the position of each transport unit with the information provided by the ATO system, and the position of each transport unit is continuously calibrated by the recognition sensors on the track; then, the real-time tracking information of each transport unit is fed back to the screen of the ATS system control center. The real-time monitoring function of the ATS system is shown in Figure 7.

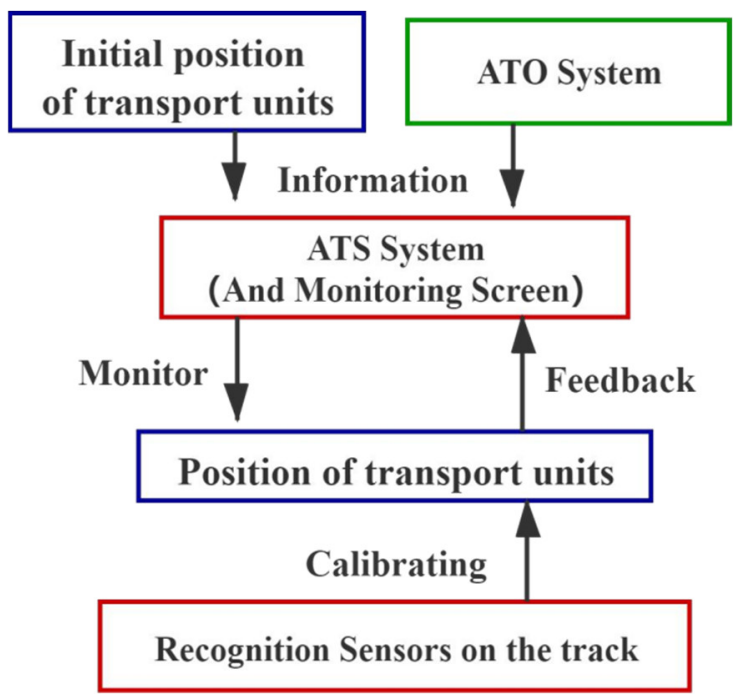

Figure 7. The real-time monitoring. 


\section{$B$. The start-up time control of the transport units}

The start-up time control of the transport units is able to improve the transport efficiency of the underground mines, and the function of the start-up time control is accomplished through the monitoring and control of the ATS system. As early as 2013, Anjomshoa et al. [41] optimized the vehicle schedules in underground mines to control the start of the transport units. In 2016, GEORGESCU [42] made the improvements to the CBTC system based on driver-less technology and Internet of Things technology, and he proposed using the ATS system of the CBTC system to realize the start and stop of the driver-less train.

To solve practical problems in the underground mines, a process based on Internet of Things technology and AI Computing has been established. When the Stope in the intelligent underground mine does not need transport operations, each transport unit needs to be on standby at the depot. Once there is a Stope that needs transport operations, the process begins running: (1) Calculate the amount of transport units that might be required in the operations. (2) The ATS system controls the transport units to the Stope to participate in transport operations with parameters such as the ATP system and ATO system to assist in controlling the speed of the transport units. (3) The whole process is fed back to the monitoring screen of the ATS system.

The whole process of the start-up time control is as shown in Figure 8.

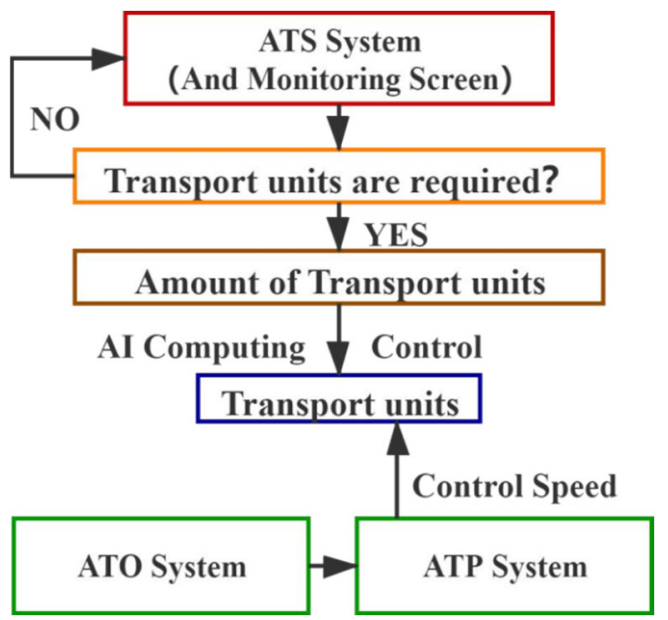

Figure 8. The start-up time control.

\section{The route adjustment of the transport units}

In intelligent underground mines, more than one concentrator is usually built, so there is always more than one unloading point for the transport units. If it is possible to choose the most suitable unloading route for each transport unit according to the traffic conditions of underground routes, the transportation efficiency of underground mines will be greatly improved.

In 2005, Gamache, Grimard, and Cohen [43] raised a shortest-path algorithm based on the AI Computing for solving the fleet management problem in underground mines, and in 2009, Li and Liu [44] published their research on underground coal mine monitoring with wireless sensor networks; the wireless sensor network was used to monitor and control the transportation route of each transport unit in the underground mine.

In recent years, many people have studied the shortest-path algorithm; Jukna and Schnitger [45] optimized it through practice and simulation, Zhiran et al. [46] mentioned its superiority in large-scale road transport, and Franceschetti et al. [47] considered that the shortest-path algorithm is very effective in transportation scheduling.

By combining the ATS system and AI Computing function as an integral whole, a process based on shortest-path algorithm has been established: (1) The integral whole of the ATS system and AI Computing analyzes the congestion of each transportation route. (2) 
When the ATS system gets feedback from the AI Computing function, it will automatically choose the best route to the unloading place for each transport unit participating in the transportation operations. (3) Meanwhile, the parameters such as the ATP system and ATO system assist in controlling the speed of the transport units. (4) The whole process is fed back to the monitoring screen of the ATS system.

The whole process of the route adjustment is as shown in Figure 9.

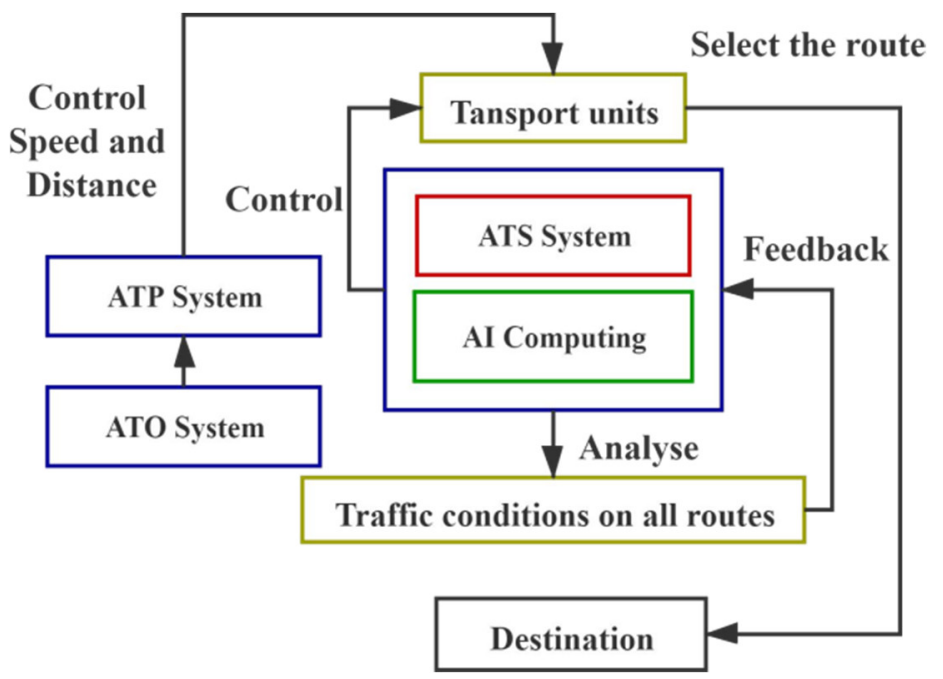

Figure 9. The route adjustment.

D. Transport units tracking

At the 2013 13th International Conference on Control, Automation and Systems (ICCAS 2013), S. Oh et al. [48] claimed that in non-CBTC systems, train position information is inaccurate and discontinuous; therefore, it is very necessary to establish the train tracking equation. For underground mine transportation, there are also such problems.

Based on the disturbance vibration and other factors, Z. Mao et al. [49] established the train compensation tracking equation in 2018. In order to solve this problem, the concept paper draws on the method of Z. Mao et al. [50] of tracking equations: The transport units location is tracked based on the ground beacon data, airborne information, Correlation Interval Algorithm, and the digraph. Specially, transport units tracking equations are established using the transport unit measurement error, track wear, and information transmission delay, as the following Equations (1) and (2) [50] show.

$$
\begin{gathered}
T_{\text {hesway of mine }(m)}=\frac{S_{b}+L_{u}+L_{u-a}}{V_{\max }} \\
S_{b}=Y_{\beta}-m
\end{gathered}
$$

Equations (1) and (2) [50] Tracking equations.

In Equations (1) and (2), $m$ represents the line mileage of the transport unit, $S_{b}$ represents the blocked area, $Y_{\beta}$ represents the mileage from $m$ to the axle counting area end, $L_{u}$ represents the length of the transport unit, $L_{u-a}$ represents the transport unit position's uncertainty amount, and $V_{\max }$ represents the transport unit's maximum allowable operating speed.

In the application of tracking equations based on the digraph, the followings are essential: (1) The digraph is stored in the linked list. (2) The ATS system receives the transport units' main information including the units' running direction, the offset and the corresponding points in the directed graph. (3) The directed graph edges and offsets at the beginning and end of the unit section are determined based on the relevant data in the packet, and then, the coordinates of the start and end of the track are found in the directed 
graph. (4) The specific position of the unit is determined according to the running direction of the unit and the edge direction of the directed graph.

\section{E. Other functions}

The ATS system of the CBTC system can also realize the functions of alarm, recording the running process of the transport units, recording running video, playback, and so on.

\section{Future Work}

Although the concept paper does a great deal of work in the function design of the CBTC system, which aims to solve the practical problems in the underground mine rail transportation, there are still a lot of weak points:

1. For the methods such as the Dynamic Fault Tree analysis method and the tracking equations, there is no further explanation of its depth and how it works with the CBTC system.

2. Although the concept paper has made a lot of effort in theoretical research, there is no practical engineering application or practice to verify the practicability of the design.

As engineers, we are focusing on the application of the technologies in the engineering; therefore, we may be not very clear about the principles of the technologies that are used in the engineering projects, but in our future work, solving the practical application of the technologies will undoubtedly be the key of our research. Here, I promise that we will continue the research with the experts who specialize in the related technologies and methods, and we will solve the above problem and explain how these technologies and methods work with the CBTC system in our future articles. The tracking equation we have established is not perfect and few factors are taken into account, so further optimization and application of the tracking equation will be carried out in our next work.

Additionally, after all the above problems have been resolved, we plan to test the design in the mining outlet roadway, which is roadway 1 in Figure 10 below. To achieve this plan, we must overcome the difficulties in theory and solve the above problem (1) thoroughly before we can apply our conceptual design to the practice.

If, with the efforts of experts and us, we overcome the theoretical problems of the design and apply it to underground mines, regardless of the results of the study, we believe that these results can bring some enlightenment to the relevant research. Here, I promise we will try our best.

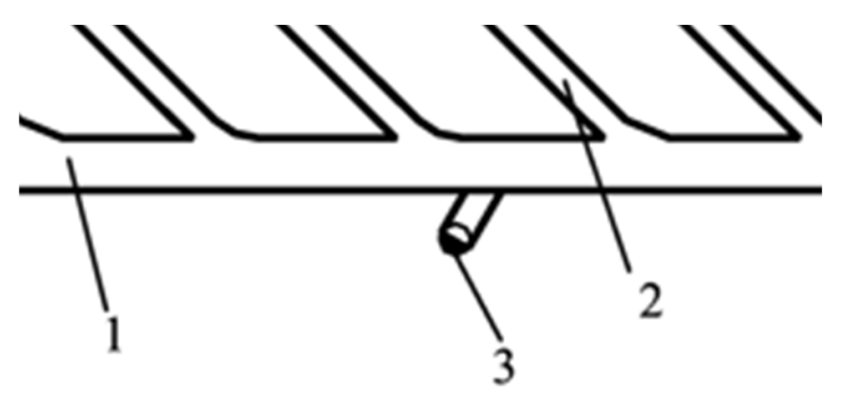

Figure 10. The roadway map (a part) of our engineering project. 1: outlet roadway; 2: mining route; 3: jack shaft.

Actually speaking, in future underground mine rail transit, there are still many challenges and opportunities.

Firstly, the rail in transportation plays an important role, even in the monitoring of rail transportation; many researchers use the information feedback from the rail to establish the tracking equation of the rail vehicle, such as the wear degree of the rail. Nardo et al. [51] studied the railway network in 2020 and considered a problem regarding the control system and a restoration time. Their research is very innovative, and their research on railway is undoubtedly a kind of enlightenment to our work and to the rail transit of underground mines in the future. 
Secondly, the optimization of the control system of underground mining vehicles is also one of the key points of future researchers. For example, we have used the Dynamic Fault Tree in our design to deal with the causality and the consecution of control systems in engineering, but System Dynamics can actually deal with similar problems better. The team of Nardo [52-55] has researched such a system model; they got great results. Munoz [56], Gonzalez [57], and Mana proposed the optimization of the security monitoring of the control systems based on cloud computing, so we believe that in the future, more and more such methods will appear and be applied to control systems.

In future underground mine transportation, the interconnection of the transport units is also the trend of the times. However, there will be a lot of uncertainty in this, so many researchers have been studying it. Muñoz and Maña [58,59] as well as Waller et al. [60] have been studying cloud computing and mobile security management, and they laid the foundation for the later realization of the interconnection of the transport units in underground mines.

Finally, the monitoring of the underground environment is also an important part in the underground transportation. The monitoring of the underground environment, such as topographic monitoring or underground gas concentration monitoring, can have a positive impact on many aspects of mine production. The topographic monitoring is beneficial to the transportation of underground vehicles, and the monitoring of underground gas concentration plays a great role in the "rescue" of underground personnel and vehicles. A lot of researchers have studied this, and most of them [61-63] are willing to use ZigBee WSN to locate underground mines and monitor gas concentration and other information.

In short, in the future development of underground mine transportation, researchers need to meet these challenges and seize the opportunities to promote the development of the industry. We believe that if we all give our full strength, then in the future, underground mine transportation will be fully intelligent.

\section{Discussion and Outlook}

The idea of an Intelligent Trackless Underground Mine has been proposed for a long time, but because of its high cost and difficulty to monitor and control, Trackless Underground transportation is not widely used, especially in the developing countries such as China. On the contrary, intelligent rail underground transportation is popular around the developing countries, not only because of its low cost but also because it is easy to monitor and control; however, there are still a large amount of problems to be solved in the intelligent rail underground transportation.

With the precedent of the application of the CBTC system to the underground subway, this concept paper started the exploration in the possibility of application of the CBTC system to the underground transportation by reviewing the related literature. This concept paper briefly reports the progress in the present stage of the research to apply the CBTC system especially the three systems to the underground transportation in order to dedicate to solving the practical problems in the engineering of transportation in underground mines.

The New Dynamic Fault Tree analysis method proposed by Gao et al. [34] at the 2020 IEEE 23rd International Conference on Intelligent Transportation Systems (ITSC) gave the inspiration to this "concept paper" to try to summarize and establish the analysis and the process of the fault event in order to solve the problem on the basis of the CBTC system.

For the practical problem of the safety rear-end collision problem in the underground mine transportation, a series of analyses of the fault events have been established to estimate and control the hidden danger of the accident with the assistance of the ATP system. Meanwhile, in the practical problem of the transport efficiency problem, just a single analysis of the fault event has been established to make the underground mine transportation achieve the maximum efficiency with the work of the ATP system and the ATO system. The results suggest that the more complex the practical problems are, the 
more the analysis of the fault events needs to be established in the New Dynamic Fault Tree analysis method, and the more complicated the diagram of the process will be.

For the practical problems of the underground mine transportation, safety and efficiency are relatively easier to solve with the assistance of the ATP system, the ATO system, and the New Dynamic Fault Tree analysis method compared to the real-time monitoring problem. As is known, the real-time monitoring of the transport units is the biggest problem in intelligent underground mines, and the ATS system of the CBTC system is the core to solve the biggest problem out of question.

In 2018, Issad et al. [64] combined the ATS system of the CBTC system with the Internet of Things technology, and they conducted a simulation in the simulation environment, achieving a good result. In fact, in 2017, that the combination of the CBTC system and Internet of Things technology would advance the CBTC system became an academic consensus [8]. Nowadays, most of the CBTC systems used in various countries are "The Products" combined with Internet of Things technology, but even such a complete CBTC system can not completely solve the problems in rail transportation of the underground mines. Thus, mainly four problems in the real-time monitoring of underground mines have been put forward by Ali et al. [39] in 2015: (1) the real-time monitoring of the transport units, (2) the start-up time control of the transport units, (3) the route adjustment of the transport units, and (4) transport units tracking.

For the real-time monitoring of the transport units, the identification of the transport units is the prerequisite for solving the problem; due to the number recognition sensors on the track and the ATS system, the identification and the monitoring of each transport unit can be realized, and the running of the whole process is fed back on the screen of the ATS system. For the start-up time control of the transport units, a similar analysis process to the Dynamic Fault Tree analysis method has been established to control each transport unit to the Stope to participate in transport operations by the ATS system. For the route adjustment of the transport units, a process based on the shortest-path algorithm [4347] has been established to adjust the running route of each transport unit to improve the transport efficiency and reduce the cost of the distance and the time. Finally, for the transport units tracking, the tracking equations based on the digraph have been established to solve the problem in which the position information of each transport unit is inaccurate and discontinuous in underground transportation.

The concept paper tries to summarize and propose the solutions to the practical problems in the engineering of transportation in underground mines with the assistance of the CBTC system; the functions of the CBTC system and its subsystems are also improved and applied to the solution of problems in the transportation of the underground mines.

However, in the future, the CBTC system might be replaced by more advanced systems. In 2016, Gurník [37] raised his prospect of the NGTC (Next Generation Train Control) project; he thought that most of the functions of the CBTC system have gradually fallen behind. In 2021, as the representative of developing countries, China's research on the NGTC (Next Generation Train Control) system is progressing rapidly, and there is even the possibility of pilot applications soon. Recently, Chinese researchers Yang and Liu [65] reported their research on the modeling and verification of the train departure scenario for the Next Generation Train Control system.

With the appearance of more and more advanced systems, the dominant position of the CBTC system in urban rail transit is likely to be gradually replaced. If the CBTC system were to be replaced in the urban rail transit control system one day, there is no doubt that the CBTC system would disappear from underground mine transportation.

For underground mine transportation, in 2015, Ali et al. [39] published their research on the development of an underground mine monitoring and communication system that integrated ZigBee (based on IEEE802.15.4) and GIS (Geographic Information System), and they inferred that ZigBee technology and GIS would be widely used in the control and communications of the underground mine transportation in the future. For the trackless transportation of underground mines, the CBTC system may also take the leading role. If 
the path of the trackless transport equipment is planned within a certain range, the CBTC system can still have good performance in the control and monitoring. Moridi [39] believes that if the low power and efficient information transmission of the ZigBee technology are applied to the underground control system, the mining industry will certainly make rapid progress; therefore, the combination of the CBTC system and ZigBee technology may be a good performance in the control and monitoring in the underground mines. As for the tracking of the underground transportation, tracking technology has made great progress in recent years. Similar to Czaplewski et al. [66], he established the tracking equations through Global Navigation Satellite System (GNSS) and Geodetic Networks in 2020. Chen et al. [67] established the tracking equations by $5 \mathrm{G}$ technology. As science and technology progress, the method of establishing tracking equations will be improved with time, such as using $5 \mathrm{G}$ technology in the establishment of tracking equations.

Munoz, Mana, and Serrano [68] present an approach to model dynamic changes in ambient intelligence scenarios using the AVISPA (automated validation of Internet security protocols and applications) model-checking tool suite in 2009. According to some reports and surveys [69], the application of this technology in all walks of life in the future will be as good as people think.

Except for the GIS and the other systems mentioned above, there are a lot of advanced monitoring and control systems emerging, such as WAMC (Wide Area Monitoring and Control) system. However, whatever control and monitoring systems emerge in the future, as long as these systems can be applied to specific practical problems and engineering projects to achieve good results, the efforts of researchers around the world who are researching the innovative system will not be in vain.

\section{Summary}

Overall, this paper is a concept paper; by summarizing the relevant literature, this paper discusses the possibility of applying the CBTC system to the monitoring and control system of underground mines, proposes the function design of the CBTC system for the solutions to the practical problems, and reports the progress in the present stage of some existing research to apply the CBTC system in the underground mines.

In the Introduction part, the paper combines the relevant literature, makes a series of analyses on the historical process and development of underground mine intelligence, and puts forward some urgent problems in underground mining: that is, the monitoring and control of underground mine transportation. Monitoring and control is always a troublesome matter for engineers in underground mines, which may not only take into account the cost and effect but also have a certain relationship with the level of local mining development. Therefore, in the Introduction, the paper puts forward the possibility of applying the CBTC system to the monitoring and control of underground transportation and summarizes the development process and the functions of the CBTC system according to the relevant literature. Specially, the paper also summarizes and collates the related documents and literature of the application of CBTC system in underground transportation, in order to find the basis for the possibility that CBTC system can be applied in underground mine transportation. In the Concept and Design section, based on several previous methods or theories, such as the Dynamic Fault Tree analysis method [34] and the shortest-path algorithm [43-47], the paper finishes the function design for the CBTC system and summarizes the solutions to three practical problems in mines: the Safety Problem, Efficiency Problem, and Monitoring and Control. In the Future Work section, the authors summarized some shortcomings in this design and proposed the plans for future research. At the same time, in the Discussion and Outlook section, the paper discusses the whole article, explains some details, and offers a vision for the future of the CBTC system and the underground mine monitoring and control systems.

Finally, the authors claim that the concept paper serves as a guide to the Tossing out a brick to get a jade gem, as it has a few implications for the development and the future of 
the underground mine transportation. It is hoped that more and more researchers will be interested and engage in the research of this field.

Author Contributions: H.Y.-Conceptualization/Writing—original draft/Writing-review and editing. S.L.-Project administration/Resources/Supervision/Software/Validation. All authors have read and agreed to the published version of the manuscript.

Funding: The authors thank the financial supports from the National Natural Science Foundation of China (51804337).

Data Availability Statement: New data were created or analyzed in this study. Data sharing is not applicable to this article.

Conflicts of Interest: The authors declare no conflict of interest.

\section{References}

1. Dong, L.; Sun, D.; Han, G.; Li, X.; Hu, Q.; Shu, L. Velocity-free localization of autonomous driverless vehicles in underground intelligent mines. IEEE Trans. Veh. Technol. 2020, 69, 9292-9303. [CrossRef]

2. Chen, W.; Wang, X. Coal mine safety intelligent monitoring based on wireless sensor network. IEEE Sens. J. 2020. [CrossRef]

3. Meng, Y.; Li, J. Research on intelligent configuration method of mine IoT communication resources based on data flow behavior. IEEE Access 2020, 8, 172065-172075. [CrossRef]

4. MacLeod, I.; Stothert, A. Distributed intelligent control for a mine refrigeration system. IEEE Control. Syst. 1998, 18, 31-38. [CrossRef]

5. Zheng, M.G.; Cai, S.J. An intelligent system for calculating the scale of rational, enlarged production of an underground non-ferrous metal mine. J. China Univ. Min. Technol. 2008, 18, 214-219. [CrossRef]

6. Zhen, L. Underground coal mine ventilation monitoring system research. Appl. Mech. Mater. 2013, 353-356, 3085-3088. [CrossRef]

7. Farooq, J.; Bro, L.; Karstensen, R.T.; Soler, J. Performance evaluation of a Multi-radio, Multi-hop Ad-hoc radio communication network for Communi-cations-Based Train Control (CBTC). IEEE Trans. Veh. Technol. 2018, 67, 56-71. [CrossRef]

8. Farooq, J.; Soler, J. Radio communication for Communications-Based Train Control (CBTC): A tutorial and survey. IEEE Commun. Surv. Tutor. 2017, 19, 1377-1402. [CrossRef]

9. IEEE Standard for User Interface Requirements in Communications-Based Train Control (CBTC) Systems. In IEEE Std 1474.2-2003; Institute of Electrical and Electronics Engineers (IEEE): Piscataway, NJ, USA, 2008; pp. 1-19.

10. IEEE Standard for Communications-Based Train Control (CBTC) Performance and Functional Requirements. In IEEE Std 1474.12004 (Revision of IEEE Std 1474.1-1999; Institute of Electrical and Electronics Engineers (IEEE): Piscataway, NJ, USA, 2008; pp. $1-45$.

11. Vantuono, W.C. CBTC-and beyond: Looking at CBTC not only as a train control system, but also in the context of an overall information, communication, monitoring, control, and management strategy. Railw. Age 2003, $204,65$.

12. Alexander, R.P.; Mortlock, E.A. Controlling and Executing Communications Based Train Control (CBTC) Installation and Testing With a CBTC-Ready Vehicle. In Proceedings of the ASME/IEEE 2005 Joint Rail Conference, Pueblo, CO, USA, 16-18 March 2005; pp. 193-198.

13. Chen, R.; Guo, J. Development of the new CBTC system simulation and performance analysis. Comput. Railw. XII 2010, 114, 497-507. [CrossRef]

14. Xie, Y.; Tang, T. Performance analysis of communication network for the CBTC system. In Proceedings of the 2009 IEEE Intelligent Vehicles Symposium , Xi'an, China, 3-5 June 2009; pp. 1072-1077. [CrossRef]

15. Bu, B.; Yang, J.; Wen, S.; Zhu, L. Predictive function control for Communication-Based Train Control (CBTC) systems. Int. J. Adv. Robot. Syst. 2013, 10, 79. [CrossRef]

16. Zhu, L.; Yu, F.R.; Ning, B.; Tang, T. Communication-Based Train Control (CBTC) systems with cooperative relaying: Design and performance analysis. IEEE Trans. Veh. Technol. 2013, 63, 2162-2172. [CrossRef]

17. Wang, H.; Yu, F.R.; Jiang, H. Modeling of radio channels with leaky coaxial cable for LTE-M based CBTC systems. IEEE Commun. Lett. 2016, 20, 1038-1041. [CrossRef]

18. Wang, X.; Liu, L.; Zhu, L.; Tang, T. Joint security and QoS provisioning in Train-Centric CBTC systems under sybil attacks. IEEE Access 2019, 7, 91169-91182. [CrossRef]

19. Liu, J.; Qian, L.; Zhang, Y.; Han, J.; Sun, J. Towards safety-risk prediction of CBTC systems with deep learning and formal methods. IEEE Access 2020, 8, 16618-16626. [CrossRef]

20. Wang, X.; Liu, L.; Zhu, L.; Tang, T. Train-Centric CBTC meets age of information in Train-to-Train communications. IEEE Trans. Intell. Transp. Syst. 2020, 21, 4072-4085. [CrossRef]

21. Wang, H.; Zhao, N.; Chen, L. An integrated capacity evaluation method for CBTC-system-equipped urban rail lines. Proc. Inst. Mech. Eng. Part F J. Rail Rapid Transit 2013, 229, 291-302. [CrossRef]

22. Sun, W.; Yu, F.R.; Tang, T.; You, S. A Cognitive control method for cost-efficient CBTC systems with smart grids. IEEE Trans. Intell. Transp. Syst. 2016, 18, 568-582. [CrossRef] 
23. Si, X.; Kuang, W.; Li, Q. A method of generating engineering test sequence for urban rail transit CBTC system based on formalization. IOP Conf. Ser. Earth Environ. Sci. 2020, 526, 12192. [CrossRef]

24. Zhu, L.; Li, Y.; Yu, F.R.; Ning, B.; Tang, T.; Wang, X. Cross-layer defense methods for jamming-resistant CBTC systems. IEEE Trans. Intell. Transp. Syst. 2020, 1-13. [CrossRef]

25. Wen, T.; Constantinou, C.; Chen, L.; Tian, Z.; Roberts, C. Access point deployment optimization in CBTC data communication system. IEEE Trans. Intell. Transp. Syst. 2018, 19, 1985-1995. [CrossRef]

26. Wang, H.; Yu, F.R.; Zhu, L.; Tang, T.; Ning, B. Finite-state markov modeling of leaky waveguide channels in Communication-Based Train Control (CBTC) systems. IEEE Commun. Lett. 2013, 17, 1408-1411. [CrossRef]

27. Carvajal-Carreño, W.; Cucala, A.P.; Fernández-Cardador, A. Fuzzy train tracking algorithm for the energy efficient operationof CBTC equipped metro lines. Eng. Appl. Artif. Intell. 2016, 53, 19-31. [CrossRef]

28. Bin, N.; Tao, T.; Min, Q.K.; Hai, G.C. CBTC (Communication Based Train Control): System and Development. In Geo-Environment and Landscape Evolution III; Witpress LTD.: Southampton, UK, 2006; Volume 88.

29. Wang, H.; Yu, F.R.; Zhu, L.; Tang, T.; Ning, B. Finite-state Markov modeling for wireless channels in tunnel communication-based train control systems. IEEE Trans. Intell. Transp. Syst. 2014, 15, 1083-1090. [CrossRef]

30. Briginshaw, D. Can CBTC cope with complex rail networks? Int. Railw. J. 2014, 54, 2.

31. Aziminejad, A.; Lee, A.W.; Epelbaum, G. Underground communication: Radio propagation prediction for CBTC data communication subsystem design. IEEE Veh. Technol. Mag. 2015, 10, 71-79. [CrossRef]

32. Circle Line junction CBTC. Railw. Gaz. Int. 2019, 175, 13.

33. Dash, A.K.; Bhattcharjee, R.; Paul, P.; Tikader, M. Study and analysis of accidents due to wheeled trackless transportation machinery in indian coal mine-Identification of gap in current investigation system. Procedia Earth Planet. Sci. 2015, 11, 539-547. [CrossRef]

34. Gao, P.; Liu, C.; Dong, H.; Zheng, W. A Dynamic Fault Tree Based CBTC Onboard ATP System Safety Analysis Method. In Proceedings of the 2020 IEEE 23rd International Conference on Intelligent Transportation Systems (ITSC), Rhodes, Greece, 20-23 September 2020; pp. 1-7.

35. Wu, W.; Bu, B. Security analysis for CBTC systems under attack-defense confrontation. Electronics 2019, 8, 991. [CrossRef]

36. Xue, J.; Wei, L.M. Research on Intelligent Track Positioning System to the Mine Accident Rescue. In Proceedings of the World Automation Congress, Puerto Vallarta, Mexico, 24-28 June 2012; pp. 1-3.

37. Gurník, P. Next Generation Train Control (NGTC): More effective railways through the convergence of main-line and urban train control systems. Transp. Res. Procedia 2016, 14, 1855-1864. [CrossRef]

38. Feng, X.; Qian, J.; Sun, Z.; Wang, X. Wireless Mobile Monitoring System for Tram Rail Transport in Underground Coal Mine Based on WMN. In Proceedings of the 2010 International Conference on Computational Aspects of Social Networks, Taiyuan, China, 26-28 September 2010; pp. 452-455.

39. Ali, M.M.; Youhei, K.; Mostafa, S.; Knox, C.E.; Markus, W.; Hyongdoo, J.; Hirokazu, O. Development of underground mine monitoring and communication system integrated ZigBee and GIS. Int. J. Min. Sci. Technol. 2015, 25, 811-818.

40. Mazzanti, F.; Ferrari, A. Ten Diverse Formal Models for a CBTC Automatic Train Supervision System. In Proceedings of the Electronic Proceedings in Theoretical Computer Science; Open Publishing Association: The Hague, The Netherlands, 2018; Volume 268, pp. 104-149.

41. Anjomshoa, H.; Albrecht, A.; Lee, D.H.; Pudney, P. Optimising passing bay locations and vehicle schedules in underground mines. J. Oper. Res. Soc. 2013, 64, 241-249. [CrossRef]

42. Georgescu, M.P. Driverless CBTC—Specific requirements for CBTC systems to overcome operation challenges. Geo-Environ. Landsc. Evol. III 2006, 88. [CrossRef]

43. Gamache, M.; Grimard, R.; Cohen, P. A shortest-path algorithm for solving the fleet management problem in underground mines. Eur. J. Oper. Res. 2005, 166, 497-506. [CrossRef]

44. Li, M.; Liu, Y. Underground coal mine monitoring with wireless sensor networks. ACM Trans. Sens. Netw. 2009, 5, 1-29. [CrossRef]

45. Jukna, S.; Schnitger, G. On the optimality of Bellman-Ford-Moore shortest path algorithm. Theor. Comput. Sci. 2016, 628, 101-109. [CrossRef]

46. Zhang, Z.; Liu, J.; Qiu, A.; Qian, X.; Zhang, F. The shortest path approximation algorithm for large scale road network. Acta Geod. Cartogr. Sin. 2019, 48,86.

47. Franceschetti, A.; Honhon, D.; Laporte, G.; Van Woensel, T. A Shortest-Path algorithm for the departure time and speed optimization problem. Transp. Sci. 2018, 52, 756-768. [CrossRef]

48. Oh, S.; Yoon, Y.; Kim, K.; Kim, Y. Design of ATP Functions and Communication Interface Specifications for Korean Radio-Based Train Control System. In Proceedings of the 2013 13th International Conference on Control, Automation and Systems (ICCAS 2013), Gwangju, Korea, 20-23 October 2013; pp. 1330-1333.

49. Mao, Z.; Tao, G.; Jiang, B.; Yan, X.-G. Adaptive actuator compensation of position tracking for high-speed trains with disturbances. IEEE Trans. Veh. Technol. 2018, 67, 5706-5717. [CrossRef]

50. Li, S.; Wang, G.; Yu, H.; Wang, X. Engineering Project: The Method to Solve Practical Problems for the Monitoring and Control of Driver-Less Electric Transport Vehicles in the Underground Mines. World Electr. Veh. J. 2021, 12, 64. [CrossRef]

51. Di Nardo, M.; Clericuzio, M.; Murino, T.; Madonna, M. An adaptive resilience approach for a high capacity railway. Int. Rev. Civ. Eng. 2020, 11, 98. [CrossRef] 
52. Di Nardo, M.; Madonna, M.; Santillo, L.C. Safety management system: A system dynamics approach to manage risks in a process plant. Int. Rev. Model. Simul. IREMOS 2016, 9. [CrossRef]

53. Di Nardo, M.; Gallo, M.; Murino, T.; Santillo, L. System dynamics simulation for fire and explosion risk analysis in home environment. Int. Rev. Model. Simul. IREMOS 2017, 10. [CrossRef]

54. Di Nardo, M.; Madonna, M.; Murino, T.; Castagna, F. Modelling a safety management system using system dynamics at the bhopal incident. Appl. Sci. 2020, 10, 903. [CrossRef]

55. Di Nardo, M.; Clericuzio, M.; Murino, T.; Sepe, C. An economic order quantity stochastic dynamic optimi-zation model in a logistic 4.0 environment. Sustainability 2020, 12, 4075. [CrossRef]

56. Muñoz, A.; Gonzalez, J.; Maña, A. A Performance-Oriented Monitoring System for Security Properties in Cloud Computing Applications. Comput. J. 2012, 55, 979-994. [CrossRef]

57. Toutouh, J.; Muñoz, A.; Nesmachnow, S. Evolution Oriented Monitoring oriented to Security Properties for Cloud Applications. In Proceedings of the 13th International Conference on Predictive Models and Data Analytics in Software Engineering 2018; ACM: New York, NY, USA, 2018; p. 32.

58. Muñoz, A.; Maña, A. TPM-based protection for mobile agents. Secur. Commun. Netw. 2010, 4, 45-60. [CrossRef]

59. Munoz, A.; Mafia, A. Software and Hardware Certification Techniques in a Combined Certification Model. In Proceedings of the 2014 11th International Conference on Security and Cryptography (SECRYPT), Vienna, Austria, 28-30 August 2014; pp. 1-6.

60. Waller, A.; Sandy, I.; Power, E.; Aivaloglou, E.; Skianis, C.; Muñoz, A.; Maña, A. Policy Based Management for Security in Cloud Computing. In FTRA International Conference on Secure and Trust Computing, Data Management, and Application; Springer: Berlin/Heidelberg, Germany, 2011; pp. 130-137.

61. Uradzinski, M.; Guo, H.; Liu, X.; Yu, M. Advanced indoor positioning using zigbee wireless technology. Wirel. Pers. Commun. 2017, 97, 6509-6518. [CrossRef]

62. Moridi, M.A.; Kawamura, Y.; Sharifzadeh, M.; Chanda, E.K.; Jang, H. An investigation of underground monitoring and communication system based on radio waves attenuation using ZigBee. Tunn. Undergr. Space Technol. 2014, 43, 362-369. [CrossRef]

63. Moridi, M.A.; Sharifzadeh, M.; Kawamura, Y.; Jang, H.D. Development of wireless sensor networks for underground communication and monitoring systems (the cases of underground mine environments). Tunn. Undergr. Space Technol. 2018, 73, 127-138. [CrossRef]

64. Issad, M.; Kloul, L.; Rauzy, A.; Berkani, K. Modeling the CBTC railway system of siemens with ScOLa. Int. J. Intell. Transp. Syst. Res. 2017, 16, 163-172. [CrossRef]

65. Yang, L.; Liu, Z. Modeling and verification of train departure scenario for next generation train control system. MATEC Web Conf. 2021, 336, 02008. [CrossRef]

66. Czaplewski, K.; Wisniewski, Z.; Specht, C.; Wilk, A.; Koc, W.; Karwowski, K.; Skibicki, J.; Dabrowski, P.; Czaplewski, B.; Specht, M.; et al. Application of least squares with conditional equations method for railway track inventory using GNSS observations. Sensors 2020, 20, 4948. [CrossRef]

67. Chen, J.J.; Hwang, Y.S.; Liao, Y.J.; Ku, Y.; Yu, C.C. A rail-to-rail ultra-wide bandwidth hybrid supply modulator for 5G applications with envelope tracking techniques. Int. J. Circuit Theory Appl. 2019, 47, 1907-1921. [CrossRef]

68. Muñoz, A.; Maña, A.; Serrano, D. AVISPA In the Validation of Ambient Intelligence Scenarios. In Proceedings of the 2009 International Conference on Availability, Reliability and Security, Fukuoka, Japan, 16-19 March 2009; pp. 420-426.

69. Sadri, F. Ambient intelligence: A survey. ACM Comput. Surv. 2011, 43, 1-66. [CrossRef] 